\title{
Future role of leprosy training and/or research institutions. ALERT, February 25-26, 1998
}

\author{
PAUL SAUNDERSON \\ ALERT, PO Box 165, Addis Ababa, Ethiopia
}

Accepted for publication 26 May 1998

This meeting, co-ordinated by WHO and ably chaired by Dr Joseph Kawuma, brought together doctors, scientists and managers from over 20 institutions in five continents, involved in leprosy work. The objectives were to review the current activities of specialized leprosy institutions in the light of changing needs; to identify feasible activities for the next 10 years; and to identify leprosy training and research needs for the future.

Ten of the major institutions made brief presentations of their current activities. These were: ALERT, Addis Ababa, Ethiopia; Marie-Adelaide Centre, Karachi, Pakistan; Alf redo da Matta Institute, Manaus, Brazil; SLRTC, Karigiri, India; JALMA Institute, Agra, India; Leonard Wood Memorial Centre, Cebu, Philippines; CLTRI, Chengalpattu, India; ILAD, Dakar, Senegal; Institut Marchoux, Bamako, Mali; and Institute Lauro de Souza Lima, Bauru, Brazil.

There were then two presentations aimed at setting the scene for the discussions. Dr James Krahenbuhl presented a paper by Dr R. R. Jacobson, Director of GWLHDC, Carville, who was not able to attend. He began with a few words about Carville, which, contrary to rumour, is not closing but is relocating to Baton Rouge - the centre remains an active department of Louisiana State University.

Dr Jacobson argued that leprosy will be with us long after the year 2000 and some expertise must be maintained in most areas beyond that date. Future activities will depend on the workload, but leprosy should be covered in all medical and paramedical training and in the appropriate textbooks. The general public should also be kept informed about leprosy through the mass media.

Looking more specifically at workload, Dr Jacobson suggested that with more than 100 new cases per year, a country might consider maintaining regional experts and a referral facility (probably part of a general hospital) for in-patient care of complicated cases. With more than 1000 new cases per year, more than one referral centre would be needed and the whole programme should be regionalized under national guidelines and oversight. This situation already exists in the United States, which may be a useful model for other low endemic countries.

Although any centre could, in theory, provide training and research, it is advisable to have at least five or six world centres of expertise for training, research, rehabilitation and advice on complex issues. 
The second presentation, by Dr Kawuma, Deputy Director of the Ugandan National TB/Leprosy Programme, looked at the relationship between institutions and national programmes. There are significant areas of overlap in both objectives and activities, but they have complimentary roles and responsibilities, with differing expertise and constraints. Even with leprosy elimination and integration, many on-going activities will be benefited by active institutions. Training has often in the past been only loosely connected to the needs of the national programme, so there is a need for better communication between the parties involved. Programme managers are usually not in a position to undertake basic research, but even health systems research would be better co-ordinated by a research institution.

In discussion, Dr Feenstra emphasized that integration did not mean the removal of specialists, but on the contrary, should make other specialists (for example, rehabilitation experts) more available to leprosy patients. Dr Chiang asked whether any success in integrating specialist leprosy services can be quoted. Dr Noordeen suggested that general staff are not reluctant to treat leprosy patients, but we are reluctant to train and hand over the work to them.

Four discussion groups were established, with initial presentations in the plenary session to set the agenda for each group. Each group then met for two sessions before reporting back to the meeting; final conclusions and recommendations were drawn up.

\section{Group A: training}

Dr Groenen asked the group to focus on the training needs of control programmes, the end-users of training, given that the current trend in prevalence means that many peripheral clinics will treat one or two cases a year, at most.

The group concluded that after confirmation of the diagnosis, the peripheral health worker should be able to administer MDT and/or steroid therapy. He/she should then be able to carry out case-holding and assist the patient in preventing further damage to hands, feet and eyes. The peripheral health worker should also be able to screen household contacts and identify suspects.

Specific leprosy expertise needs to be available to one or more staff in the general health system at the district level, regardless of the leprosy prevalence. Essential skills required at the district level are as follows:

1. Diagnose leprosy and prescribe proper treatment regimen.

2. Diagnose and manage leprosy reactions.

3. Supervise and provide on the job training to peripheral health workers.

4. Ensure proper recording and reporting.

5. Manage and/or refer other leprosy related complications.

The specific role of leprosy institutions is to provide the specialist training required at the regional and national levels. The added value of these leprosy institutions is that such training can be offered through interaction with leprosy hospital services, leprosy control, research and rehabilitation programmes.

\section{Group B: referral services and field work}

Dr Fajardo outlined the future requirements of field work. The group emphasized the 
transfer of skills to the intermediate level of the general health services, with effective two-way communication. If achieved, this will enable the referral centres to effectively implement training, research activities and diversification, depending upon the context and resources available.

\section{Group C: prevention of disability and rehabilitation}

Dr Virmond introduced the topic in the context of integration, mentioning the need for further research. The group suggested that training of intermediate level staff, better communication and agreed standards of care should be priorities. Networking with centres outside the leprosy field, involved in the management of other types of disability, is recommended.

\section{Group D: research}

Dr Ji divided future research priorities into two areas: research for improving patient care (comprising improved implementation of MDT, early detection of nerve damage and management of reactions and neuritis) and research for post-elimination strategies (comprising epidemiology, chemotherapy and basic research). The group stressed operational research, done in conjunction with national programmes, as a priority. They emphasized diversification and increased interaction with other research fields to enrich the intellectual and possibly the financial climate of future leprosy research.

\section{Conclusion}

During the final debate, Dr Groenen argued for an expert committee to draw up detailed guidelines for the training of peripheral health workers. The general feeling, however, was that this should be done in each country, taking into account local conditions. Another hotly debated issue was diversification: how important is this for leprosy institutions? Most participants felt it is the only route to survival. Professor Britton felt that public education should be a priority, but the meeting concluded that this is the responsibility of the national programmes, not the institutions. Professor Smith raised the interesting scenario that after elimination and a possible decline in the capacity of the general health services to manage leprosy, the institutions may be required to play a more prominent role than is expected at present.

The conclusions and recommendations of the meeting were summarized as follows:

1. In view of the rapidly changing situation of leprosy and the increasing integration of leprosy work within the general health services, the role of leprosy training and research institutions needs to be redefined.

2. The essential roles of training, service and research need to be retained, with a renewed focus on elimination and post-elimination issues.

3. All future activities must have close collaboration and two-way communication with national leprosy control programmes. 
4. Leprosy institutions should network with other centres involved in training, research and rehabilitation, including those outside the field of leprosy.

5. The institutions will continue to provide the required expertise to train leprosy specialists at the national and regional levels and to provide advice to the national programmes on training at district and peripheral levels. The training should be decentralized, task-oriented and as short as possible.

6. In order to preserve expertise and sustain tertiary referral services for leprosy patients in a cost-effective manner, institutions should consider diversifying according to local capacity and needs.

7. The institutions should take the lead in proposing appropriate standards and guidelines for the prevention and management of disabilities, and the rehabilitation of persons affected by leprosy.

8. There remains a need for continued research into improving patient care and operational research into elimination issues. Capacity, particularly for operational research, needs to be built up. Basic research in leprosy should be maintained.

In closing, Dr Noordeen thanked ALERT and the Government of Ethiopia for hosting the gathering. 